\title{
New comparative clinical and biometric findings between acute primary angle-closure and glaucomatous eyes with narrow angle
}

\author{
Novos achados comparativos clínicos e biométricos entre olhos com fechamento angular \\ primário agudo e olhos glaucomatosos com seio camerular estreito
}

Rafael Vidal Mérula ${ }^{1}$, Sebastião Cronemberger ${ }^{2}$, Alberto Diniz Filho ${ }^{1}$, Nassim Calixto ${ }^{2}$

\section{ABSTRACT}

Purpose: To compare, clinically and biometrically, affected and fellow acute primary angle-closure (APAC) eyes and glaucomatous eyes with narrow angle (NA).

Methods: Comparative case series: 30 patients with APAC and 27 glaucomatous patients with NA were evaluated. Keratometry (K), central corneal thickness $(C C T)$, lens thickness $(L T)$, axial length $(A L)$ and anterior chamber depth (ACD) were measured. Parameters defined as lens posisiton (LP) and relative lens position (RLP) were calculated.

Results: Biometric difference between APAC-affected and fellow eyes was found only in $\mathrm{LP}(P=0.046)$. When fellow eyes were compared to glaucomatous eyes with NA, differences were found in ACD $(P=0.009), \mathrm{AL}(P=0.010)$, and $\mathrm{LT} / \mathrm{AL}$ $(P=0.005)$. The comparison between APAC-affected and glaucomatous eyes with NA showed significant differences in almost all biometric parameters, except for $\operatorname{LT}(P=0.148)$ and $\operatorname{RL} P(P=0.374)$. We found that the logistic regression model (LRM), built with three parameters (K, CCT and LT/AL), higher than 0.334 could be a reasonable instrument to differentiate APAC eyes from glaucomatous eyes with NA.

Conclusions: This study showed that APAC-affected and fellow eyes have similar biometric features, and glaucomatous eyes with NA have a less crowded anterior segment. The LRM built showed promising results in distinguishing APAC from glaucomatous eyes with NA.

Keywords: Glaucoma, angle-closure; Anterior chamber; Biometry

\section{RESUMO}

Objetivo: Comparar, clinica e biometricamente, olhos acometidos por fechamento angular primário agudo (FAPA) com seus contralaterais e olhos com glaucoma primário de ângulo aberto e estreito.

Métodos: Série de casos comparativos: 30 pacientes com FAPA e 27 glaucomatosos com ângulo estreito (AE) foram avaliados. Olhos afetados por FAPA e seus contralaterais foram analisados. Ceratometria (K), espessura corneana central (ECC), espessura do cristalino (CR), diâmetro antero-posterior do olho (AXL), e profundidade central da câmara anterior (PCA) foram medidos. PC (posição do cristalino) e PRC (posição relativa do cristalino) foram calculadas. Resultados: Diferença biométrica entre olhos afetados por FAPA e seus contralaterais foi encontrada somente na $P C(P=0,046)$. Quando os olhos contralaterais foram comparados com os olhos glaucomatosos com $A E$, diferenças foram encontradas na PCA $(P=0,009)$, AXL $(P=0,010)$, e $C R / A X L(P=0,005)$. A comparaça entre os olhos afetados e os olhos glaucomatosos com AE mostrou diferenças significativas em quase todos os parâmetros biométricos, exceto na $C R(P=0,148)$ e $P R C(P=0,374)$. Verificamos que o modelo de regressão logística $(M R L)$, construído com 3 parâmetros (K, ECC e CR/AXL), quando apresenta valores maiores de 0,334 pode ser um instrumento razoável para diferençar olhos com FAPA de olhos glaucomatosos com AE.

Conclusões: O presente estudo mostrou que olhos afetados por FAPA e seus contralaterais apresentam características biométricas similares, e olhos glaucomatosos com AE apresentam um segmento anterior menos aglomerado. O MRL construido mostrou resultados promissores para diferençar olhos COM FAPA de olhos glaucomatosos com AE.

Descritores: Glaucoma de ângulo fechado; Câmara anterior; Biometria

\section{INTRODUCTION}

$\mathrm{t}$ is estimated that 66.8 million people are affected by primary glaucoma worldwide, and nearly half of these is due to primary angle-closure glaucoma (PACG) $)^{(1)}$. Acute primary angle-closure (APAC) is a potentially blinding form of the disease. The incidence of APAC is particularly high in Asiatic populations $s^{(2-3)}$.

Work carried out at the Glaucoma Service, São Geraldo Hospital, Clínicas Hospital, Federal University of Minas Gerais - UFMG - Belo Horizonte (MG), Brazil.

${ }^{1}$ Physician, Glaucoma Service, São Geraldo Hospital, Clínicas Hospital, Federal University of Minas Gerais - UFMG - Belo Horizonte (MG), Brazil.

2 Physician, Discipline of Ophthalmology, Medicine School, Federal University of Minas Gerais - UFMG - Belo Horizonte (MG), Brazil.

Correspondence address: Rafael Vidal Mérula. Rua Espírito Santo, 1.315 - Apto. 402 - Juiz de Fora (MG) - CEP 36016-200 - E-mail: rafaelmerula@hotmail.com

Recebido para publicação em 13.03.2010

última versão recebida em 25.10.2010

Aprovação em 13.11.2010

Nota Editorial: Depois de concluída a análise do artigo sob sigilo editorial e com a anuência do Dr. Roberto Pedrosa Galvão Filho sobre a divulgação de seu nome como revisor, agradecemos sua participação neste processo.
Ocular biometric studies have shown that APAC eyes, compared to normal eyes, have shorter axial length $(A L)^{(4-9)}$, shallower anterior chamber ${ }^{(4-5,7-9)}$, smaller radius of anterior corneal curvature(10), smaller radius of posterior corneal curvature $^{(11)}$, smaller radius of anterior lens curvature ${ }^{(12)}$, thicker lens ${ }^{(8,13)}$, more anterior lens position $(L P)^{(14)}$, and higher lens thickness (LT) to ocular axial length ratio ${ }^{(15)}$. One study has demonstrated that APAC eyes have higher central corneal thickness (CCT), shallower anterior chamber depth (ACD), thicker lens and more anterior LP compared to sub acute and chronic PACG ${ }^{(16)}$, and other study has verified that shallower ACD and shorter AL are found in APAC eyes compared with primary openangle glaucoma (POAG) eyes ${ }^{(17)}$. Some researchers concluded that affected eyes, compared to fellow eyes, have shallower $A C D^{(16-18)}$, more anterior LP(18), less cortical opacity ${ }^{(18)}$, and lower relative lens position (RLP) values.

However, our knowledge about the pathophysiology of the angle closure is still incomplete. So, we decided to perform a clinical and biometric comparison among eyes that have an anatomic feature in common (narrow angle), eyes with the diagnosis of primary open-angle glaucoma (POAG) with 
narrow angle (NA), affected and fellow eyes of patients with APAC.

\section{METHODS}

Patients were recruited from the Glaucoma Service of São Geraldo Hospital of the Federal University of Minas Gerais (FUMG) from September, 2005 to June, 2007. The study was carried out after approval from the FUMG Research Ethics Committee and informed consent was obtained from all patients. The following criteria were used to define cases of APAC: 1) presence of at least two of the following symptoms: ocular or periocular pain, nausea and/or vomiting, previous history of intermittent blurring of vision with halos; and 2) presenting intraocular pressure (IOP) of more than $28 \mathrm{mmHg}$ (Goldmann applanation tonometry) and the presence of at least three of the following signs: conjunctival injection, corneal epithelial edema, mid-dilated unreactive pupil, and shallow anterior chamber; and 3) the presence of a closed angle in the affected eye, verified by gonioscopy. Exclusion criteria used were the following: no nuclear sclerosis defined as Lens Opacities Classification System (LOCS) II less than grade 2 (NC2, NO2)(19); secondary glaucoma; plateau iris configuration (PIC) (ultrasound biomicroscopy examination, performed in all eyes, must show the ciliary processes anteriorly located, closing the ciliary sulcus, and providing structural support behind the peripheral iris); unresolved APAC due to unresponsiveness to medical treatment; and previous surgical procedure in one or both eyes. The group of NA was composed by patients with the diagnosis of POAG with narrow angle. The criteria used to define POAG with narrow angle were: 1) IOP higher than $21 \mathrm{mmHg}$; and 2) presence of glaucomatous optic neuropathy defined by at least two of the following items, cup-disc asymmetry between fellow eyes greater than 0.2, rim thinning, notching, cup/disc ratio (C/D) equal or more than 0.7 , optic disc haemorrhage or retinal nerve fiber layer (RNFL) defect; and 3) glaucomatous visual field defects detected by automated perimetry evaluated by means of Octopus 1-2-3 (moderate criteria of Caprioli) (20); and 4) narrow open angle evaluated by gonioscopy. Exclusion criteria used were the following: no nuclear sclerosis defined as LOCS II less than grade 2 (NC2, NO2)(19); secondary glaucoma; PIC as described above; signs of previous glaucoma acute attack, such as sectorial iris atrophy, "glaukomflecken", or peripheral anterior synechia; corneal opacity in both eyes; requirement of surgical procedure to control IOP; and previous surgical procedure in both eyes. If no exclusion criteria were found in any eye, the right eye was preferably evaluated.

Gonioscopy was done by one of the authors (R.V.M.) and confirmed by another investigator (S.C.), using a Goldmann 3 mirror goniolens, and a Zeiss four-mirror goniolens to perform indentation gonioscopy, in the undilated state under room light illumination (approximately 240 lux, ) and dark (approximately 0.1 lux) conditions which were uniform for all examination. The gonioscopy classification currently used by the Glaucoma Service, both in primary gaze and under indentation, was adopted in this study and applied under room light illumination: 1) wide open angle (angle totally open); 2) intermediate open angle (when it was possible to see until scleral spur, but it was not possible to identify the ciliary band); 3 ) narrow open angle (when it was only possible to identify the anterior part of the trabecular meshwork); 4) closed angle (it was not possible to identify any structure). The angle was fully gonioscopically evaluated $\left(360^{\circ}\right)$, and the classification of at least $270^{\circ}$ of the angle was adopted to label the gonioscopy of each eye.

More than 60 hours after the acute attack was resolved with reduction of IOP, improvement of corneal clarity and absence of symptoms, the APAC-affected and fellow eyes were evaluated. Laser peripheral iridotomy was performed in both affected and fellow eyes just after examination.

Clinical examination consisted of history, visual acuity with and without optical correction, biomicroscopy, gonioscopy and eye fundus examination. Biometric parameters were captured by A-mode contact ultrasonography (DGH 5100e; DGH Technologies, Exton, USA) and consisted of ACD, LT and AL, additionally, CCT and average keratometry $(K)$ value from vertical and horizontal measurements were evaluated by an ultrasonic pachymetry (DGH 5100e; DGH Technologies, Exton, USA) and Bausch \& Lomb keratometer, respectively. Measurements were performed until three consecutive readings with a standard deviation of $\leq 0.05 \mathrm{~mm}$ were obtained for A-mode ultrasonography parameters and with a standard deviation of $\leq 5 \mu \mathrm{m}$ were obtained for ultrasonic pachymetry. Ratio between $L T$ and $A L$ was defined as $L T / A L$, lens position (LP) was defined as $A C D+1 / 2 L T$ and relative lens position (RLP) was defined as $\mathrm{LP} / \mathrm{AL}$.

Statistical analysis was performed using 13.0 SPSS. We have used frequency histograms and the following tests: one-sample Kolmogorov-Smirnov, Student's t, paired Student's t, MannWhitney $U$, Wilcoxon and Pearson's chi-square. A $p$ value of less than 0.05 was considered statistically significant.

Three variables (K, CCT and $L T / A L)$ in which the differences between APAC fellow and NA eyes were at least marginally statistically significant ( $p$ value lower than 0.10 ) were used to build a logistic regression model, aimed to predict the risk of APAC. The criteria of selection of variables to the model have taken into account marginal significance $(p<0.10)$ and also to avoid situations of collinearity - independent variables should be actually uncorrelated.

The calibration of this model was performed with the aid of Hosmer\&Lemeshow test, and three variables - K, CCT and $L T / A L$ remained in the model specified below:

$$
\ln (P / 1-P)=\beta_{0}+\beta_{1} K+\beta_{2} C C T+\beta_{3} L T / A L
$$

where

In - natural logarithm

$P$ - probability of the event

$\beta$ - value of regression coefficients

Receivers operating characteristic (ROC) curves were calculated using MedCalc Software for Windows (Medalc Software, Inc., Mariakerke, Belgium). Receiver operating characteristic curves of the logistic regression model and all parameters in which statistical differences were found between APAC fellow and NA eyes were constructed. The best relation sensitivity/specificity was assessed by the definition of cut-off points.

\section{RESULTS}

One thousand four hundred and forty-three patients were attended at the glaucoma service from September, 2005 to June, 2007. Thirty patients (7.9\%) from the 380 emergency cases had the diagnosis of APAC, so an incidence of 78.9/1000 emergency patients were attended. No patient showed bilateral APAC during the study. Twenty-seven patients with the diagnosis of POAG with NA were included in this study.

The demographic features of the 57 subjects who were included in the study are shown in table 1. NA patients were older than APAC patients $(p=0.006)$, however, no difference was found in the other parameters.

Table 2 shows the clinical characteristics, gonioscopy, KM and CCT. Except for C/D ratio $(p=0.103)$, the other clinical features were significantly different between the two subgroups of APAC. On the contrary, just C/D was statistically different $(p<0.001)$ when fellow eyes were compared to NA 
eyes. With statistical difference, the APAC-affected eyes had a higher $K$ value than fellow eyes $(p=0.027)$ and NA eyes $(p=0.010)$, also the $K$ value of the fellow eyes was statistically

Table 1. Demographic characteristics of APAC and NA patients

\begin{tabular}{lccc}
\hline & $\begin{array}{c}\text { APAC } \\
\mathbf{n}=\mathbf{3 0}\end{array}$ & $\mathbf{n}=\mathbf{2 7}$ & P value \\
\hline Age (yrs) & $58.9 \pm 9.3$ & $65.9 \pm 9.0$ & $0.006^{\mathrm{a}}$ \\
Gender & & & $0.820^{\mathrm{b}}$ \\
\% Male & $23.3(7)$ & $25.9(7)$ & \\
\% Female & $76.7(23)$ & $74.1(20)$ & \\
Race & & & $0.438^{\mathrm{b}}$ \\
\% Leukodermic & $60.0(18)$ & $48.1(13)$ & \\
\% Feodermic & $36.7(11)$ & $40.8(11)$ & \\
\% Melanodermic & $3.3(1)$ & $11.1(3)$ & \\
Family history of glaucoma & & & $0.656^{\mathrm{b}}$ \\
\% Positive & $23.3(7)$ & $18.5(5)$ & \\
\% Negative & $76.7(23)$ & $81.5(25)$ & \\
\hline
\end{tabular}

$\mathrm{APAC}=$ acute primary angle closure; $\mathrm{NA}=$ narrow angle; ${ }^{\mathrm{a}}=$ independent samples Student's $t$ test; ${ }^{b}=$ chi-square test higher than the value of NA eyes $(p=0.034)$. There was no significant difference between APAC-affected and fellow eyes when CCT was evaluated ( $p=0.571$ ), however NA eyes demonstrated a thinner $C C T$, with statistical significance, when compared to APAC-affected eyes $(p=0.015)$ and fellow eyes $(p=0.023)$.

Table 3 shows the ocular echobiometric parameters. Statistically significant difference between the APAC-affected and fellow eyes was found only in the LP ( $p=0.046)$. When fellow eyes were compared to NA eyes, statistical differences were found in $\operatorname{ACD}(p=0.009), \operatorname{AL}(p=0.010)$, and LT/AL ( $p=0.005)$. The comparison between APAC-affected and NA eyes showed significant differences in all biometric parameters, except for $\operatorname{LT}(p=0.148)$ and RLP $(p=0.374)$.

Keratometry, CCT and LT/AL in which the differences between APAC fellow and NA eyes were at least marginally statistically significant $(p<0.10)$ were used to construct the logistic regression model, and they showed â values of 0.335 (Confidence Interval (Cl) 95\%: 0.026-0.744), 0.021 (Cl 95\%: 0.001-0.040), and 4.294 (Cl 95\%: 0.611-8.747), respectively, and $p$ values of $0.080,0.036$ and 0.039 , respectively.

The highest value of the area under the ROC curve was found in the logistic regression model $(0.80 \pm 0.06)$ (Table 4, Figures 1-3). The logistic regression model higher than 0.334

Table 2. Clinical characteristics, gonioscopy, keratometry and paquimetry of APAC-affected and fellow eyes, and NA eyes; and significance ( $p$ values) among various groups

\begin{tabular}{|c|c|c|c|c|c|c|}
\hline & \multicolumn{3}{|c|}{ Group statistics } & \multirow{2}{*}{$\frac{P \text {-value (dependent) }}{\begin{array}{c}\text { Affected vs } \\
\text { fellow }\end{array}}$} & \multicolumn{2}{|c|}{$P$-value (independent) } \\
\hline & $\begin{array}{c}\text { Affected } \\
n=30\end{array}$ & $\begin{array}{l}\text { Fellow } \\
n=30\end{array}$ & $\begin{array}{c}\text { NA } \\
n=27\end{array}$ & & $\begin{array}{c}\text { Fellow vs } \\
\text { NA }\end{array}$ & $\begin{array}{c}\text { Affected vs } \\
\text { NA }\end{array}$ \\
\hline Uncorrected visual acuity (logMAR) & $1.39 \pm 1.28$ & $0.37 \pm 0.57$ & $0.40 \pm 0.32$ & $<0.001^{\mathrm{a}}$ & $0.112^{d}$ & $<0.001^{\mathrm{d}}$ \\
\hline Corrected visual acuity (logMAR) & $1.19 \pm 1.41$ & $0.14 \pm 0.55$ & $0.14 \pm 0.27$ & $<0.001^{a}$ & $0.099^{d}$ & $<0.001^{\mathrm{d}}$ \\
\hline Spherical equivalent (dioptres) & $+0.53 \pm 1.48$ & $+1.09 \pm 1.41$ & $+1.28 \pm 1.95$ & $0.001^{\mathrm{a}}$ & $0.718^{d}$ & $0.109^{d}$ \\
\hline$C / D$ & $0.40 \pm 0.16$ & $0.37 \pm 0.13$ & $0.60 \pm 0.21$ & $0.103^{b}$ & $<0.001^{e}$ & $<0.001^{e}$ \\
\hline \multicolumn{7}{|l|}{ Gonioscopy } \\
\hline Primary Position of Gaze & & & & $0.100^{c}$ & $<0.001^{c}$ & $<0.001^{c}$ \\
\hline \% Narrow open angle*(n) & $23.3(7)$ & $43.3(13)$ & $100(27)$ & & & \\
\hline$\%$ Closed angle $\mathrm{e}^{*}(\mathrm{n})$ & $76.7(23)$ & $56.7(17)$ & $0.0(0)$ & & & \\
\hline Under Indentation & & & & $0.002^{c}$ & $<0.001^{c}$ & $<0.001^{c}$ \\
\hline$\%$ Wide open angle*(n) & $10.0(3)$ & $13.3(4)$ & $70.4(19)$ & & & \\
\hline$\%$ Intermediary open angle*(n) & $33.3(10)$ & $76.7(23)$ & $25.9(7)$ & & & \\
\hline$\%$ Narrow open angle*(n) & $50.0(15)$ & $10.0(3)$ & $3.7(1)$ & & & \\
\hline$\%$ Closed angle*(n) & 6.7 ( 2) & $0.0(0)$ & $0.0(0)$ & & & \\
\hline Keratometry (dioptres) & $45.30 \pm 1.88$ & $45.05 \pm 1.82$ & $44.08 \pm 1.48$ & $0.027^{b}$ & $0.034^{e}$ & $0.010^{e}$ \\
\hline $\mathrm{CCT}(\mu \mathrm{m})$ & $535 \pm 35$ & $533 \pm 33$ & $514 \pm 26$ & $0.571^{b}$ & $0.023^{e}$ & $0.015^{e}$ \\
\hline
\end{tabular}

Values are means $\pm \mathrm{SD} ; \mathrm{APAC}=$ acute primary angle closure; $\mathrm{NA}=$ narrow angle; $\mathrm{C} / \mathrm{D}=$ cup disc ratio; ${ }^{*}=$ refer to text; $C C T=$ central corneal thickness; ${ }^{\mathrm{a}}=\mathrm{Wil}$ coxon paired test;

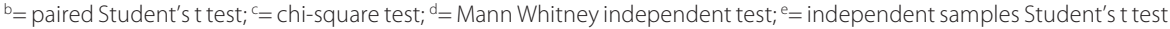

Table 3. Biometric characteristics of APAC-affected and fellow eyes, and NA; and significance ( $p$ values) among various groups

\begin{tabular}{|c|c|c|c|c|c|c|}
\hline & \multicolumn{3}{|c|}{ Group statistics } & \multirow{2}{*}{ 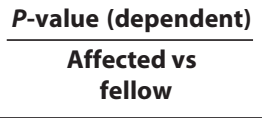 } & \multicolumn{2}{|c|}{$P$-value (independent) } \\
\hline & $\begin{array}{c}\text { Affected } \\
n=30\end{array}$ & $\begin{array}{l}\text { Fellow } \\
n=30\end{array}$ & $\begin{array}{c}\text { NA } \\
n=27\end{array}$ & & $\begin{array}{c}\text { Fellow vs } \\
\text { NA }\end{array}$ & $\begin{array}{c}\text { Affected vs } \\
\text { NA }\end{array}$ \\
\hline Anterior chamber depth (mm) & $2.42 \pm 0.28$ & $2.48 \pm 0.31$ & $2.71 \pm 0.32$ & $0.052^{b}$ & $0.009^{e}$ & $0.001^{d}$ \\
\hline Lens thickness (mm) & $4.85 \pm 0.32$ & $4.88 \pm 0.36$ & $4.73 \pm 0.29$ & $0.539^{a}$ & $0.105^{e}$ & $0.148^{e}$ \\
\hline Axial length (mm) & $21.74 \pm 0.97$ & $21.83 \pm 0.87$ & $22.44 \pm 0.87$ & $0.330^{b}$ & $0.010^{e}$ & $0.006^{e}$ \\
\hline Lens thickness/axial length ratio (LT/AL) & $2.23 \pm 0.16$ & $2.24 \pm 0.18$ & $2.11 \pm 0.15$ & $0.861^{b}$ & $0.005^{e}$ & $0.004^{e}$ \\
\hline Lens position (mm) & $4.84 \pm 0.26$ & $4.92 \pm 0.30$ & $5.07 \pm 0.31$ & $0.046^{b}$ & $0.059^{e}$ & $0.004^{e}$ \\
\hline Relative lens position & $0.22 \pm 0.13$ & $0.22 \pm 0.11$ & $0.23 \pm 0.14$ & $0.134^{b}$ & $0.807^{e}$ & $0.374^{e}$ \\
\hline
\end{tabular}

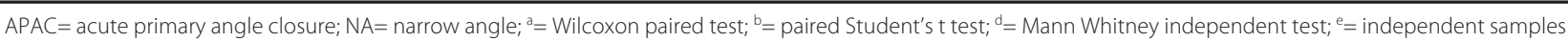
Student's t test 

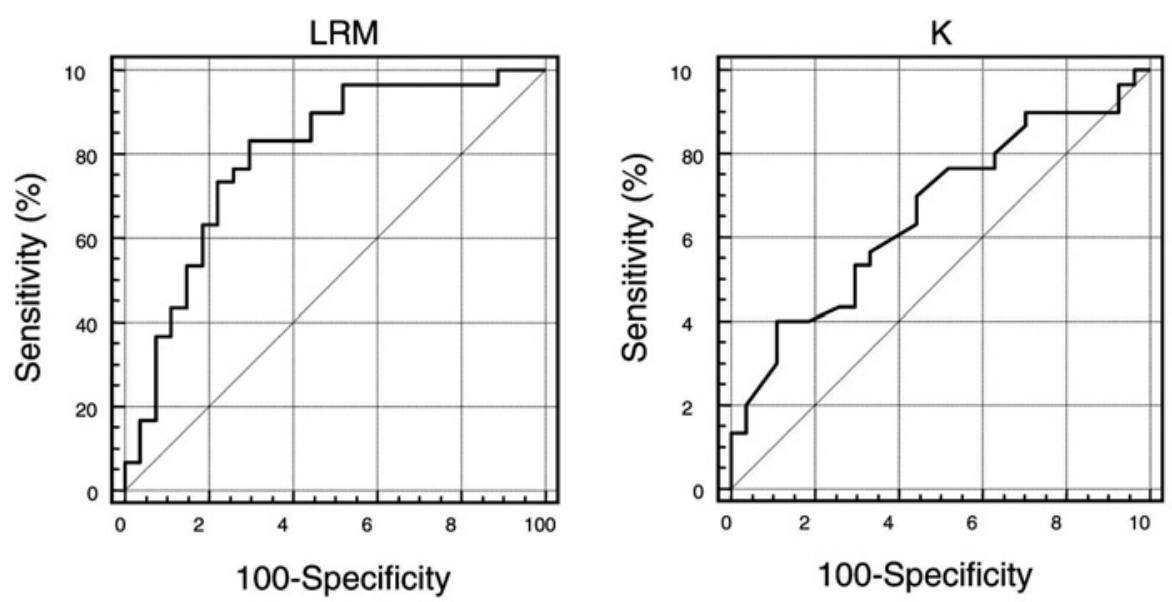

Figure 1. Receiver operating characteristic (ROC) curve of the logistic regression model (LRM) and average keratometry (K).
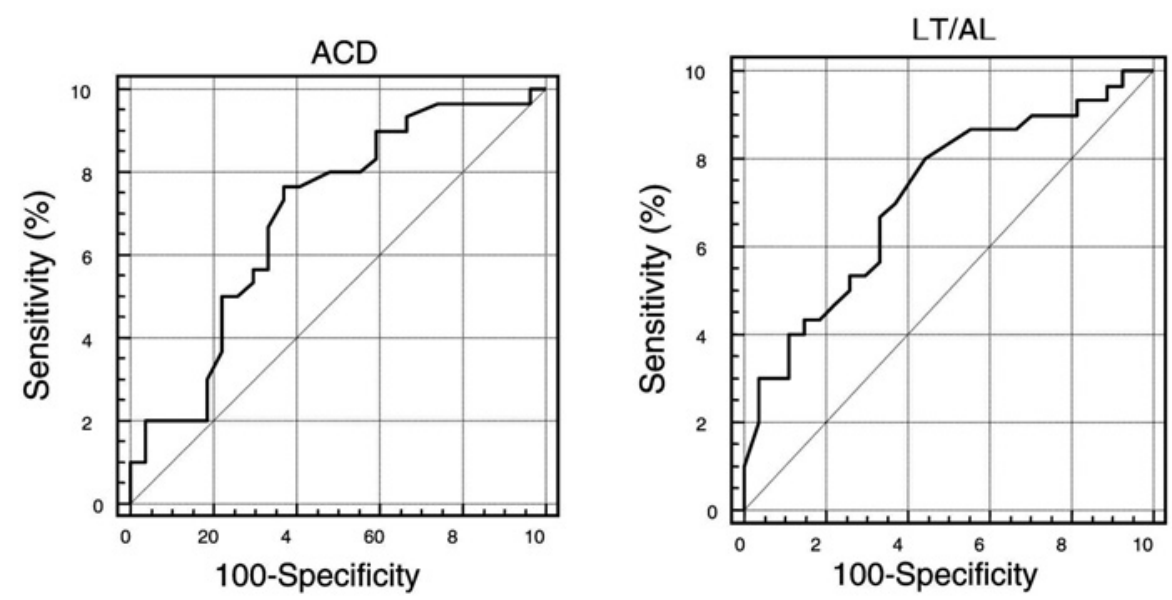

Figure 2. Receiver operating characteristic (ROC) curve of anterior chamber depth (ACD) and ratio lens thickness/ axial length (LT/AL).
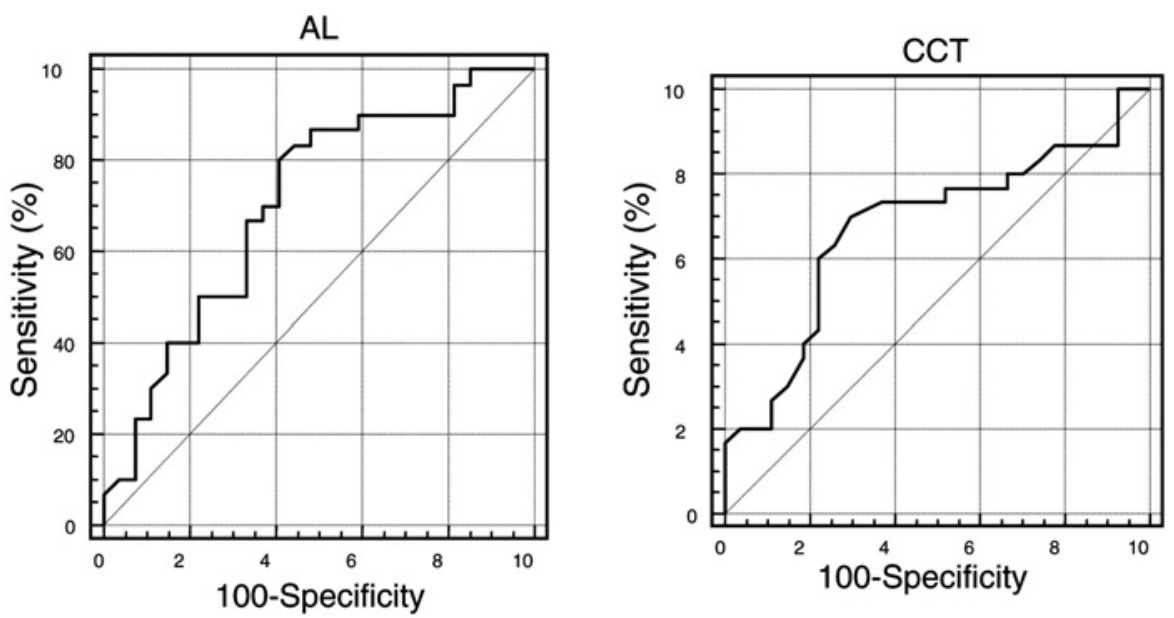

Figure 3. Receiver operating characteristic $(R O C)$ curve of axial length $(A L)$ and central corneal thickness (CCT).

could be a promising indicator to discriminate eyes with morphological characteristics similar to APAC fellow eyes from eyes with POAG with narrow angles, and probably, for prophylactic LPI (Table 4).

\section{DISCUSSION}

To the best of our knowledge, this is the first study that compared clinical characteristics, gonioscopy, K, CCT and echobiometric parameters among APAC-affected and fellow 
Table 4. The sensitivity, specificity and area under ROC curve of the logistic regression model and biometric data in predicting the risk of APAC

\begin{tabular}{lcccccc}
\hline & LRM $>\mathbf{0 . 3 3 4}$ & $\mathbf{K}>\mathbf{4 4 . 0 0}$ & $\mathbf{A C D} \leq \mathbf{2 . 6 1}$ & $\mathbf{L T} / \mathbf{A L}>\mathbf{2 . 0 9}$ & $\mathbf{A L} \leq \mathbf{2 2 . 5 4}$ & $\mathbf{C C T}>\mathbf{5 2 3}$ \\
\hline Sensitivity (\%) & 83.3 & 70.0 & 76.7 & 80.0 & 80.0 & 70.0 \\
Specificity (\%) & 70.4 & 55.6 & 63.0 & 55.6 & 59.3 & 70.4 \\
Area under ROC curve (mean \pm std deviation) & $0.80 \pm 0.06$ & $0.66 \pm 0.07$ & $0.69 \pm 0.07$ & $0.72 \pm 0.07$ & $0.70 \pm 0.07$ & $0.68 \pm 0.07$ \\
\hline
\end{tabular}

$\mathrm{APAC}=$ acute primary angle closure; $\mathrm{LRM}=$ logistic regression model; $\mathrm{K}=$ average keratometry; $\mathrm{ACD}=$ anterior chamber depth; $\mathrm{LT} / \mathrm{AL}=$ lens thickness/axial length ratio; $\mathrm{AL}=$ axial length; $\mathrm{CCT}=$ central corneal thickness

eyes, and eyes with the diagnosis of POAG with NA (NA eyes group). Except for the age, both groups had similar demographic characteristics (Table 1). The APAC patients had a mean age of $58.9 \pm 9.3$ years which was lower than the mean age of the NA patients $(65.9 \pm 9.0$ years) $(p=0.003)$. This difference could be considered a limitation of this study owing to the fact that some changes in the structure of the eye occur when people grow old ${ }^{(21-22)}$. However, the differences in the anatomical features between the $6^{\text {th }}$ and $7^{\text {th }}$ decades, which are the decades of the majority of patients included in this study, are not so significant ${ }^{(21,23-24)}$.

In this study, we have made several novel observations about APAC and narrow angle eyes. First, the hypermetropic spherical equivalent values were lower in the APAC-affected group than in the fellow group with statistical difference (Table 2). Perhaps it could be explained by the fact that APACaffected eyes showed steeper corneas than the fellow eyes (Table 2). In agreement with other studies ${ }^{(14,25)}$, the hypermetropic spherical equivalent was the most common refraction finding in angle-closure glaucoma patients, however, this paper is the first suggesting a correlation between spherical equivalent and $\mathrm{K}$ in patients with narrow angles. The NA eyes demonstrated a higher C/D than the other groups with statistical difference (Table 2). This is probably related to the fact that POAG is a chronic disease with a later diagnosis. Although all the groups had narrow or closed angles, gonioscopic classification was only similar in primary position of gaze between APAC-affected and fellow eyes (Table 2). In our study, APAC-affected and fellow eyes had similar CCT values; however, both had thicker corneas compared to NA eyes. Some authors reported that the CCT was significantly greater in acute angle-closure eyes in comparison to chronic angle-closure and normal eyes ${ }^{(16)}$

The echobiometric features in our series of patients with APAC were similar to other study reports ${ }^{(8-9,16-18,21,23-25)}$. In agreement with other studies ${ }^{(6,8,26)}$, we found that echobiometric characteristics of eyes with angle closure were well correlated with their fellow eyes, which are known to have a high incidence of APAC if left untreated (Table 3). One author documented that without treatment, 58 of 113 patients developed an acute attack in the contralateral eye, one third of these occurring in the first year ${ }^{(27)}$. Another author reported that 43 of 72 second eyes not treated with LPI went on to develop some form of angleclosure glaucoma ${ }^{(28)}$.

The ocular echobiometric data of APAC-affected eyes compared to NA eyes showed statistically significant differences in almost all features except for LT and RLP (Table 3). The APAC-affected eyes had shallower anterior chamber, shorter $A L$, more anterior $L P$ and higher values of $L T / A L$ than NA eyes (Table 3). These characteristics have already been found in other studies that compared PACG with normal controls or POAG subjects $s^{(4,7-8,14,17)}$. However, when APAC fellow eyes were compared to NA eyes statistically significant differences were found only in three parameters: ACD, AL and LT/AL (Table 3). However, the shorter $A L$ and the higher values of $L T / A L$ in
APAC fellow eyes compared to NA eyes could explain the shallower ACD in fellow eyes.

It is known that the APAC fellow eyes should be treated with LPI in order to avoid an acute crisis of angle-closure ${ }^{(27-28)}$, nevertheless, this treatment is not free of complications and side effects. Several provocative tests have been employed to try to identify patients at risk of developing acute angleclosure glaucoma, but most of them are either not very sensitive ${ }^{(29-30)}$ or time-consuming, and thus not suitable as screening procedures in general practice. Some authors suggested that an increase of a single parameter (LT/AL) is correlated with a decrease in duration in time to the need for $\mathrm{LPI}\left({ }^{(30)}\right.$. Therefore, we decided to use three parameters (K, CCT and LT/AL) to build a logistic regression model, with the aim to predict the risk of APAC in the fellow eye, and as a result, try to identify the eyes with narrow angle which we should perform LPI treatment. The logistic regression model with values above 0.334 can distinguish an APAC fellow eye from a NA eye with $83.3 \%$ of sensitivity and $70.4 \%$ of specificity, and could be at least a reasonable indicator for prophylactic LPI among the eyes evaluated in this study (Table 4). As a matter of fact, more studies are necessary to validate and improve the efficacy of this logistic regression model.

Some authors reported that the biometric values of optimal sensitivity and specificity calculated from a comparative evaluation of PACG patients and nonglaucomatous subjects were AL less than $22.80 \mathrm{~mm}$ (76\%-sensitivity, 80\%-specificity), ACD less than $2.70 \mathrm{~mm}$ (94\%-sensitivity, 94\%-specificity), or ACD/AL ratio less than 0.12 (94\%-sensitivity, 89\%-specificity), which could be good indicators for LPI; however, the control group did not have narrow angle $\mathrm{e}^{(7)}$.

A possible limitation of this study is that some eyes with APAC (only the affected eyes) were using topical myotics and it could interfere in some parameters such as ACD and LT. As a matter of fact, topical myotic was avoided if possible and, in some cases, its use was interrupted 6 to 8 hours before the examinations. Other topical ocular hypotensive medications were preferably used.

In conclusion, APAC-affected eyes showed lower hypermetropic spherical equivalent values and steeper corneas than fellow and NA eyes; moreover, APAC-affected and fellow eyes had thicker corneas than NA eyes. This study shows that APACaffected and fellow eyes have similar biometric features. The logistic regression model built with three variables ( $K, C C T$ and $L T / A L$ ) to try to predict the risk of APAC among patients with narrow angle may be a valuable tool. However, comparisons with a higher number of patients from different countries and longitudinal studies are required to further its validity and utility.

\section{REFERENCES}

1. Quigley HA. Number of people with glaucoma worldwide. Br J Ophthalmol. 1996;80(5):389-93. Comment in: Br J Ophthalmol. 1996;80(5):385-6. Br J Ophthalmol. 1997;81(1):93. 
2. Seah SK, Foster PJ, Chew PT, Jap A, Oen F, Fam HB, Lim AS. Incidence of acute primary angle-closure glaucoma in Singapore. An island-wide survey. Arch Ophthalmol. 1997;115(11):1436-40.

3. Lai JS, Liu DT, Tham CC, Li RT, Lam DS. Epidemiology of acute primary angle-closure glaucoma in the Hong Kong Chinese population: prospective study. Hong Kong Med J.2001;7(2):118-23.

4. Lowe RF. Aetiology of the anatomical basis for primary angle-closure glaucoma. Biometrical comparisons between normal eyes and eyes with primary angleclosure glaucoma. Br J Ophthalmol. 1970;54(3):161-9.

5. Alsbirk PH. Primary angle-closure glaucoma. Oculometry, epidemiology, and genetics in a high risk population. Acta Ophthalmol Suppl. 1976;(127):5-31.

6. Lowe RF. Primary angle-closure glaucoma: a review of ocular biometry. Aust J Ophthalmol. 1977;5(1):9-17

7. Lin YW, Wang TH, Hung PT. Biometric study of acute primary angle-closure glaucoma. J Formos Med Assoc. 1997;96(11):908-12

8. George R, Paul PG, Baskaran M, Ramesh SV, Raju P, Arvind H, et al. Ocular biometry in occludable angles and angle closure glaucoma: a population based survey. $\mathrm{Br}$ Ophthalmol. 2003;87(4):399-402

9. Ramani KK, Mani B, Ronnie G, Joseph R, Lingam V. Gender variation in ocular biometry and ultrasound biomicroscopy of primary angle closure suspects and normal eyes. J Glaucoma. 2007;16(1):122-8.

10. Lowe RF, Clark BA. Radius of curvature of the anterior lens surface. Correlations in normal eyes and in eyes involved with primary angle-closure glaucoma. $\mathrm{Br} \mathrm{J}$ Ophthalmol. 1973;57(7):471-4

11. Lowe RF, Clark BA. Posterior corneal curvature. Correlations in normal eyes and in eyes involved with primary angle-closure glaucoma. Br J Ophthalmol. 1973;57(7):464-70

12. Tornquist R. Corneal radius in primary acute glaucoma. Br J Ophthalmol. 1957; 41(7):421-4.

13. Phillips Cl, Storey JK. Glaucoma geometry. Exp Eye Res. 1971;11(1):140-1.

14. Lowe RF. Causes of shallow anterior chamber in primary angle-closure glaucoma. Ultrasonic biometry of normal and angle-closure glaucoma eyes. Am J Ophthalmol. 1969;67(1):87-93.

15. Markowitz SN, Morin JD. The ratio of lens thickness to axial length for biometric standardization in angle-closure glaucoma. Am J Ophthalmol. 1985;99(4): $400-2$
16. Sihota R, Lakshmaiah NC, Agarwal HC, Pandey RM, Titiyal JS. Ocular parameters in the subgroups of angle closure glaucoma. Clin Experiment Ophthalmol. 2000; 28(4):253-8.

17. Calixto N, Cronemberger S. Glaucoma simples $x$ glaucoma agudo: estudo ecobiométrico. Arq Bras Oftalmol. 1986;49(1):1-8.

18. Lim MC, Lim LS, Gazzard G, Husain R, Chan YH, Seah SK, Aung T. Lens opacity, thickness, and position in subjects with acute primary angle closure. J Glaucoma. 2006;15(3):260-3

19. Chylack LT Jr, Leske MC, McCarthy D, Khu P, Kashiwagi T, Sperduto R. Lens opacities classification system II (LOCS II). Arch Ophthalmol. 1989;107(7):991-7.

20. Caprioli J. Discrimination between normal and glaucomatous eyes. Inves Ophthalmol Vis Sci. 1992;33(1):153-9.

21. Lim KJ, Hyung SM, Youn DH. Ocular dimensions with aging in normal eyes. Korean J Ophthalmol. 1992;6(1):19-31

22. Lütjen $\mathrm{E}$, Rohen JW. [Histometric studies of the chamber angle region of the human eye in various age groups and glaucoma types]. Albrecht Von Graefes Arch Klin Exp Ophthalmol. 1968;176(1):1-12. German.

23. Markowitz SN, Morin JD. Angle-closure glaucoma: relation between lens thickness, anterior chamber depth and age. Can J Ophthalmol. 1984;19(7):300-2.

24. Fontana ST, Brubaker RF. Volume and depth of the anterior chamber in the norma aging human eye. Arch Ophthalmol. 1980;98(10):1803-8

25. Ducasse A, Mathot E, Segal A, Favre F, Burette A. [Epidemiologic aspects of acute glaucoma crisis. Study carried out at the CHR of Reims]. Ophtalmologie. 1987;1(4): 533-5. French.

26. Friedman DS, Gazzard G, Foster P, Devereux J, Broman A, Quigley H, et al. Ultrasonographic biomicroscopy, Scheimpflug photography, and novel provocative tests in contralateral eyes of Chinese patients initially seen with acute angle closure. Arch Ophthalmol. 2003;121(5):633-42.

27. Lowe RF. Acute angle-closure glaucoma: the second eye: an analysis of 200 cases. Br J Ophthalmol. 1962;46(11):641-50.

28. Snow JT. Value of prophylactic peripheral iridectomy on the second eye in angleclosure glaucoma. Trans Ophthalmol Soc UK. 1977;97(1):189-91

29. Harris LS, Galin MA. Prone provocative testing for narrow angle glaucoma. Arch Ophthalmol. 1972:87(5):493-6.

30. Hung PT. Provocation and medical treatment in post-iridectomy glaucoma. J Ocul Pharmacol. 1990;6(4):279-83.

\title{
34옹 Simpósio Internacional Moacyr Álvaro - SIMASP
}

\author{
17 a 19 de fevereiro de 2011 \\ Maksoud Plaza Hotel \\ São Paulo - SP
}

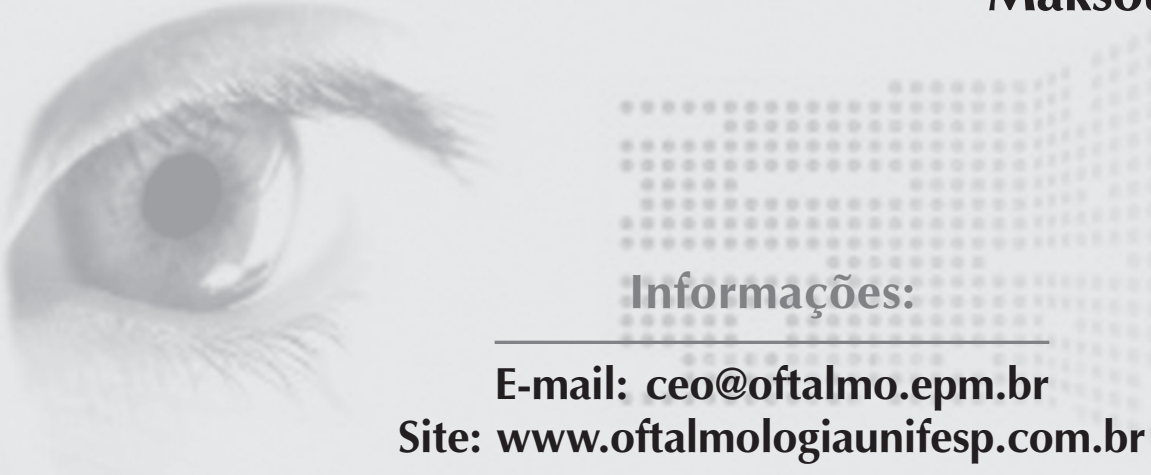

